\title{
Tres retos de la comunicación para el cambio social
}

\author{
Alfonso Gumucio Dagrón (Consorcio de Comunicación \\ para el Cambio Social, EE.UU.)
}

Recibido 29/5/2007

Aprobado 30/6/2007

\begin{abstract}
RESUMEN: Tres retos principales enfrenta la comunicación para el cambio social, tanto en el ámbito académico como en el campo del desarrollo: nombrar las cosas, desarrollar la disciplina y legitimar la comunicación para el cambio social entre las grandes agencias que toman las decisiones. Se está creando una mayor conciencia de que los programas solamente pueden ser sostenibles si las comunidades - los "beneficiarios" - se apropian de ellos, pero ese proceso solo es posible con el concurso de una comunicación que las fortalezca desde su voz, identidad y cultura.
\end{abstract}

Palabras clave: Cambio social - desarrollo - participación - identidad

\section{Three communications challenges for social change}

SuMMARY: Communication for social change faces three mayor challenges both in the academic environment and in the development field: naming things, developing discipline and to legitimize the communication for social change in the big agencies that make important decisions. A greater awareness regarding that programs can only be sustainable if the communities - the " beneficiaries" - take over them, but this take-over-through-participation-process is only possible in the event that a communication witch strengthen the communities from there voice, identity and culture appears.

Key words: Social change - development - participation - identity 
E aporte de América Latina como región pionera en la comunicación para el desarrollo y como pionera en la generación tanto de prácticas concretas como de pensamiento crítico es significativo. Tenemos pensamiento crítico sobre la comunicación para el cambio social (CCS) y para la comunicación desde el desarrollo, desde la perspectiva de participación; esa es nuestra ventaja notable.

Hemos puesto en práctica experiencias interesantísimas en niveles locales, nacionales y regionales, y hemos probado que una comunicación cuyo eje es la participación ciudadana o comunitaria, una comunicación verdaderamente participativa, basada en el diálogo, garantiza un desarrollo social apropiado y sostenible. Utilizo el término "apropiado" de manera deliberada, no como "adecuado" sino como el resultado de un proceso de apropiación social. Y digo "sostenible" pensando en todas aquellas experiencias que ahora pueden prescindir de insumos externos, y que se desarrollan con la fuerza propia de sus actores sociales.

Hay muchos retos hacia el futuro, pero quiero referirme solamente a tres: el reto de nombrar las cosas, el reto de continuar desarrollando el campo como disciplina $y$, finalmente, el reto de legitimar la CCS entre las grandes agencias que toman las decisiones del desarrollo.

\section{El reto de nombrar las cosas}

Cuando uno aprende a escuchar se da cuenta de cuáles son los obstáculos que hacen difícil el diálogo con otros actores. Uno de estos obstáculos son las palabras. Alguien decía que las palabras sirven para confundir. Si palabras sencillas, las que nombran objetos cotidianos, pueden causar a veces confusión, con mayor razón aquellas que nombran conceptos, ideas, abstracciones. Si digo "información", "comunicación" o "participación", ¿qué significados sugiero en cada uno de los que escuchan? Cada palabra es una convención, es decir, un acuerdo consensual que deviene en norma por el uso. A través de la historia nos hemos puesto de acuerdo en nombrar las cosas por un nombre, en las seis mil lenguas que todavía hay en el mundo, y la norma se ha encargado de establecer esos términos de uso. Usamos las palabras y nombramos ciertas cosas de una manera que no significa lo mismo para todos. Por ejemplo, la palabra "participación" (participación popular o participación comunitaria) no la entienden todos de la misma manera. Hoy, incluso el Banco Mundial la utiliza en sus programas de desarrollo, pero entiende el término más bien como "acceso".

Palabras como "información" y "comunicación" - que utilizamos todos los días - no las entendemos de la misma manera ni siquiera los que 
compartimos los mismos ideales sobre la comunicación para el desarrollo. Por ejemplo, uno escucha a colegas referirse a los "medios de comunicación masiva", para referirse a los medios de "difusión masiva" o de "información masiva". Yo prefiero rescatar la raíz etimológica y conceptual de la palabra, communio, del latín, que quiere decir compartir, participar, fortalecer en conjunto... Entonces me pregunto si parte de nuestros desacuerdos y divergencias, y también la falta de diálogo con las organizaciones de desarrollo, no viene en parte de esta falta de acuerdos sobre lo que significan palabras claves que están incorporadas en la jerga cotidiana del desarrollo y de nuestra profesión.

Si la comunicación es un proceso de intercambio y de diálogo, ¿no deberíamos ser más cuidadosos al usar la palabra "comunicación" para referirnos a los medios masivos? ¿No sería mejor ponernos de acuerdo en que son medios de información (aunque a veces de "desinformación") y medios de difusión? ¿No podríamos hacer un esfuerzo para preservar la palabra "comunicación" para nombrar los procesos de intercambio horizontales, procesos de participación y de comunión en el sentido de compartir?

Las grandes organizaciones de desarrollo con frecuencia usan indistintamente "comunicación" o "información" para referirse, por ejemplo, a campañas de corte publicitario sobre los temas que promueven. El frondoso vocabulario de la comunicación para el desarrollo, usado generosamente en documentos de la mayoría de las organizaciones para el desarro1lo, confunde los instrumentos (radio, prensa, televisión, publicidad) y mensajes (artículos, programas de radio o televisión, campañas) con los procesos comunicativos que implican diálogo, debate y participación.

Creo que es más importante establecer las diferencias entre términos que muchos colegas confunden sin pensarlos:

- información y comunicación;

- mensajes y procesos;

- acceso y participación;

- comunicación y comunicaciones;

- periodistas y comunicadores, e

- información y conocimiento.

Para decirlo en pocas palabras: la comunicación es un proceso horizontal de diálogo e interacción, en dos o múltiples sentidos, mientras que la información es solamente diseminación o difusión. Los mensajes son el principal producto de los periodistas, mientras que los procesos de comunicación están en el centro del trabajo facilitador de los comunicadores. El acceso es controlado por aquellos que realmente son dueños de los medios, mientras que la participación significa la apropiación del proceso de comunicación y de la toma de decisiones. La información obviamente no es lo 
mismo que el conocimiento, porque el conocimiento se hace en cada uno de nosotros y en cada comunidad a partir de la información recibida, cuando esta es puesta en diálogo con nuestra cultura y con información previa.

Finalmente, la confusión entre "comunicaciones" (en plural) y "comunicación" en singular - que es muy común en inglés - podría zanjarse fácilmente si los colegas acudieran con más frecuencia a un diccionario. El plural de la palabra se refiere a: "a: un sistema (como el de teléfonos) para comunicar, b: un sistema de rutas para trasladar tropas, suministros y vehículos...", mientras que en singular la comunicación es "un proceso por el cual se intercambia información entre individuos a través de un sistema común de símbolos, signos o comportamiento" ...

\section{El reto de desarrollar la disciplina}

El campo de la CCS sigue siendo un campo en desarrollo. No hay nada definitivo ni establecido en letras de molde. En materia de ideas, nuestra región sigue viviendo de prestado desde la década de 1950, a pesar de todo lo que ha avanzado nuestro pensamiento y nuestra práctica desde entonces. ¿No es paradójico que los estudiantes de comunicación de hoy sigan leyendo las teorías de la difusión de innovaciones de Everett Rogers, cuando él mismo revisó críticamente sus aportes en 1976 y reconoció la influencia de los pensadores latinoamericanos?

Seguimos usando acríticamente una terminología que hemos heredado de los autores estadounidenses que fueron pioneros en el campo. Repetimos, traducimos y vulgarizamos conceptos que provienen de las técnicas de publicidad comercial e incluso de las técnicas de propaganda utilizadas durante la Segunda Guerra Mundial. De ahí que en la jerga de la comunicación para el desarrollo sea tan difícil evitar, sobre todo en inglés, el uso de términos militares como "campaña" o "blanco", y de la publicidad, como "márketing", "oferta", "demanda" o "clientes".

La confusión de términos aumentó hace tres décadas, cuando las carreras de periodismo cambiaron de nombre para convertirse en carreras de "comunicación social". El problema es que solamente cambiaron de nombre, pero mantuvieron su orientación hacia los medios comerciales de difusión masiva (radio, televisión, prensa), sin incorporar contenidos de comunicación para el desarrollo y conceptos afines a los procesos comunicativos.

El campo de estudio de la CCS es distinto al campo de la información y de las relaciones públicas, y por lo tanto merece desarrollarse como una disciplina separada.

La situación actual de los estudios académicos sobre información y comunicación es preocupante. Apro- 
ximadamente, hay en el mundo más de dos mil universidades que ofrecen estudios de periodismo (más de 600 en América Latina), orientados hacia los medios de difusión, no hacia los procesos de comunicación, y apenas una veintena de programas académicos que ofrecen opciones para formar comunicadores para el desarrollo y el cambio social, estrategas de la comunicación antes que técnicos capaces de elaborar mensajes para los medios.

Existe un profundo desencuentro entre las instituciones de desarrollo (agencias internacionales, ONG, gobierno) y el ámbito académico. Hay una necesidad de profesionales de la comunicación especializados en desarrollo que las universidades no satisfacen, y eso hace que las organizaciones para el desarrollo mantengan su visión conservadora y reductora de la comunicación, entendida - en el mejor de los casos - como diseminación de información y generalmente como instrumento para dar visibilidad y presencia a las instituciones.

\section{El reto de legitimar la CCS entre los grandes}

Además de desarrollar y fortalecer la disciplina en el campo académico, necesitamos legitimarla y jerarquizarla en las organizaciones para el desarrollo. Esto de "jerarquizar" la comunicación no es una posición elitista. No se trata de despreciar o minimizar la importancia de miles de comunicado- res intuitivos, formados en la práctica social, perfectamente capaces de llevar adelante procesos de comunicación participativa en el ámbito comunitario. Como hemos señalado anteriormente, hay miles de comunicadores comunitarios que emergen de procesos participativos; las radios mineras de Bolivia y tantas otras han sido semilleros de comunicadores. El tema de jerarquizar a los comunicadores debe leerse desde una perspectiva política, y tiene que ver con la necesidad de posicionar en un nivel más alto de la agenda la CCS y el desarrollo. Si analizamos la situación actual, podremos entender mejor este aspecto.

Las organizaciones de desarrollo continúan contratando periodistas como oficiales de relaciones públicas que generalmente no tienen acceso a los niveles de decisión, y son apenas "soldados" que realizan tareas menores (conferencias de prensa, boletines, comunicados, relaciones con los medios, etcétera), pero no intervienen en la planificación estratégica de la comunicación como un componente programático. Por ello se requiere un nuevo perfil de comunicador, con visión estratégica de la CCS y con un nivel académico más alto, para participar en el proceso de toma de decisiones.

La necesidad de estos estrategas de la comunicación no invalida el importante papel que cumplen los comunicadores de base, equivalente al de los "médicos descalzos", cuya vincula- 
ción con las comunidades es esencial para lograr procesos de participación. Sin embargo, estos comunicadores de base y activistas sociales carecen de oportunidades de trabajo si es que en los más altos niveles no se diseñan estrategias que promuevan la CCS.

Necesitamos más comunicadores para el cambio social con maestrías y doctorados, pero no para que permanezcan enseñando en el ámbito de la universidad, sino para que intervengan al mismo nivel que los decisores, en las estrategias de comunicación para el desarrollo. Los comunicadores no deben seguir siendo la quinta rueda del carro, de importancia secundaria en las organizaciones para el desarrollo. Tres indicadores serían suficientes para determinar en qué nivel de la agenda de prioridades está la comunicación en las instituciones de desarrollo:

- El porcentaje del presupuesto institucional y programático destinado a la comunicación (no a la información ni a las relaciones públicas).

- El nivel de los puestos creados para especialistas en comunicación (no para relacionistas públicos).

- La decisión de desarrollar políticas y estrategias de comunicación.

No es de extrañarse que sin presupuesto y sin especialistas en comunicación, tampoco encontremos políti- cas y estrategias al respecto. Lo más que tienen las organizaciones, en su mayoría, son "planes" que se reducen a listas de actividades de información o relaciones públicas sin relación con áreas programáticas. Su prioridad siempre son los "medios", y eso, en el mejor de los casos, puede incluir formación de periodistas para "sensibilizarlos" sobre los temas del desarrollo. No hay políticas que aborden los procesos de comunicación de largo plazo, porque todas las agencias tienen objetivos de largo plazo, pero agendas de corto plazo, tristemente definidas por los plazos de rotación de los directores. Es necesario establecer procesos de fiscalización y mecanismos de control social sobre las organizaciones para el desarrollo, y observatorios como los que se han creado para vigilar el comportamiento de los medios masivos.

Si un enfoque más amplio y estratégico de la CCS fuera adoptado por las grandes agencias de desarrollo, estas podrían influir positivamente en los estados para aprobar leyes que protejan y promuevan el derecho a la comunicación, y de ese modo neutralizar a las empresas privadas que tienen afanes monopólicos en el campo de la información. Tendríamos un horizonte muy diferente si las grandes instituciones para el desarrollo contaran con políticas de apoyo a la CCS y al derecho de los pueblos a comunicar. 